\title{
JOURNAL.RU
}

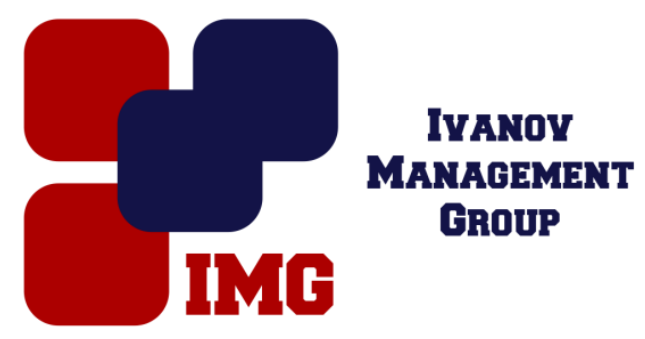

Ильяшенко В.В.

Уральский государственный экономический университет Екатеринбург, Россия

doi: $10.18411 / 1 \mathrm{j}-31-07-2017-49$

idsp 000001:1j-31-07-2017-49

\section{Инфляция спроса и издержек в современной российской экономике}

\section{Аннотация}

В статье рассматриваются инфляционные процессы в российской экономике. Показана преобладающая роль инфляции издержек в современной экономике России. Приведены и проанализированы статистические данные, подтверждающие эту особенность на уровне Федеральных округов Российской Федерации.

Ключевые слова: инфляция спроса, инфляция издержек, монетаристская теория, совокупный спрос, антиинфляционная политика.

Развитие инфляции вызвано многими факторами, которые в определенных экономических условиях проявляются по-разному и могут действовать в противоположных направлениях. Поэтому методы, эффективные для снижения инфляции спроса, в ситуации преобладания инфляции издержек могут способствовать ее развитию и возникновению различных негативных социально-экономических процессов.

Как известно, инфляция спроса развивается в результате увеличения совокупного спроса (совокупных расходов) и имеет монетарный характер, вызвана увеличением предложения денег. С позиции экономической теории механизм еe развития отражает монетаристский подход к исследованию инфляционных процессов, когда инфляция рассматривается как чисто денежное явление. Инфляцию издержек обычно связывают с факторами, влияющими на 
рост средних и предельных издержек производства, снижение совокупного предложения, что объективно влияет на повышение цены единицы продукции.

Монетаристская теория объясняет инфляцию, основываясь на взаимосвязи темпов прироста денежного предложения и уровня цен. Однако проведенный нами анализ показал, что в российской экономике прямая зависимость между темпами инфляции и приростом денежного агрегата М2 по сравнению с предыдущим годом, соответствующая монетаристской теории, наблюдалась в 2000-е гг. за 17 лет только в 2000 г., 2003 г., 2005 г., 2008 г., 2012 г. и 2013 г.

В Российской Федерации, как показали наши исследования, преобладает инфляция издержек. В наибольшей степени она проявляется в кризисные периоды российской экономики.

Жесткая рестрикционная денежная политика, которая обычно используется для преодоления инфляции в России, оказывает определенное влияние на снижение темпов инфляции. Так, в 2016 г. темп инфляции снизился до 5,6\%. Но борьба с инфляцией только монетаристскими методами не должна быть самоцелью, так как снижение уровня инфляции и ее трансформация в инфляцию издержек сочетаются с крайне негативными для экономики последствиями: сокращением темпов развития производства или его спадом, снижением инвестиционных расходов, сокращением уровня жизни населения. Так, по данным Росстата, в 2015 г. физический объем ВВП снизился на 2,8\%, в 2016 г. - на 0,2\%; инвестиции в основной капитал в 2015 г. сократились на 10,1\%, в 2016 г. - на 0,9\%; реальные доходы населения в 2015 г. уменьшились на $3,2 \%$, в 2016 г. - на 5,9\%; оборот розничной торговли снизился в 2015 г. на $10,0 \%$, в 2016 г. - на 5,2\%.

Особенности инфляционных процессов в российской экономике проявляются и на региональном уровне.

Мы проанализировали динамику показателей, влияющих на инфляцию спроса и издержек, в 2016 г. по сравнению с 2015 г. по Федеральным округам Российской Федерации для подтверждения отмеченных ранее особенностей развития инфляционных процессов в РФ. Данные приведены в таблицах 1 и 2. 
Таблицча 1.

Индексы показателей, влияющих на инфлящуию спроса, в 2016 г. по сравнению с 2015 г. в Федеральных округах

Российской Федерации, в \%

\begin{tabular}{|c|c|c|c|c|c|}
\hline \multirow[b]{2}{*}{ Федеральный округ } & \multirow[b]{2}{*}{$\begin{array}{c}\text { Индекс } \\
\text { потреби- } \\
\text { тельских } \\
\text { цен }\end{array}$} & \multicolumn{4}{|c|}{ Показатели, влияющие на инфляцию спроса } \\
\hline & & $\begin{array}{c}\text { Индекс } \\
\text { среднеме- } \\
\text { сячной } \\
\text { номиналь-ной } \\
\text { начислен-ной } \\
\text { заработной } \\
\text { платы }\end{array}$ & $\begin{array}{c}\text { Индекс } \\
\text { оборота } \\
\text { рознич-ной } \\
\text { торговли }\end{array}$ & $\begin{array}{c}\text { Индекс } \\
\text { инвес- } \\
\text { тиций в } \\
\text { основной } \\
\text { капитал }\end{array}$ & $\begin{array}{c}\text { Индекс } \\
\text { расходов } \\
\text { консолиди- } \\
\text { рованных } \\
\text { бюджетов }\end{array}$ \\
\hline & 105,6 & 107,8 & 94,8 & 99,1 & 104,8 \\
\hline \multicolumn{6}{|l|}{$\begin{array}{c}\text { Российская Федерация } \\
\text { в т.ч. }\end{array}$} \\
\hline Центральный & 106,0 & 109,3 & 94,4 & 98,7 & 108,1 \\
\hline Северо-Западный & 105,6 & 108,4 & 96,9 & 108,3 & 110,5 \\
\hline Южный & 105,4 & 107,5 & 97,6 & 83,6 & 126,3 \\
\hline \multicolumn{6}{|l|}{ Северо-Кавказский } \\
\hline Приволжский & 105,3 & 104,8 & 97,1 & 96,3 & 100,1 \\
\hline Уральский & 104,8 & 106,0 & 95,8 & 92,3 & 107,4 \\
\hline Сибирский & 105,8 & 106,2 & 92,7 & 108,8 & 101,9 \\
\hline \multirow[t]{2}{*}{ Дальневосточный } & 105,5 & 105,8 & 94,6 & 95,8 & 103,0 \\
\hline & 105,7 & 106,8 & 97,5 & 97,1 & 96,8 \\
\hline
\end{tabular}

Из таблицы 1 видно, что показатели индексов оборота розничной торговли и инвестиций в основной капитал не могли стать причиной развития инфляции спроса в 2016 г., так как в основном снизились в Федеральных округах по сравнению с 2015 г. Рост среднемесячной номинальной начисленной заработной платы мог повлиять на развитие инфляции. Однако данный показатель влияет не только на инфляцию спроса, но и на инфляцию издержек, поскольку заработная плата является не только доходом, но и составной частью затрат на производство. Единственный показатель, который мог однозначно повлиять на развитие инфляции спроса в 2016 г., - это индекс расходов консолидированных бюджетов. 
Индексы показателей, влияющих на инфлящию издержек, в 2016 г. по сравнению с 2015 г. в Федеральных округах

\begin{tabular}{|c|c|c|c|c|c|}
\hline \multirow[b]{3}{*}{ Федеральный округ } & \multicolumn{5}{|c|}{ Российской Федераичии } \\
\hline & \multirow[b]{2}{*}{$\begin{array}{c}\text { Индекс } \\
\text { потреби- } \\
\text { тельских } \\
\text { цен }\end{array}$} & \multicolumn{4}{|c|}{ Показатели, влияющие на инфляцию издержек } \\
\hline & & $\begin{array}{c}\text { Индекс цен в } \\
\text { добыче } \\
\text { полезных } \\
\text { ископа- } \\
\text { емых }\end{array}$ & $\begin{array}{c}\text { Индекс цен в } \\
\text { производ- } \\
\text { стве и } \\
\text { распреде- } \\
\text { лении } \\
\text { электро- } \\
\text { энергии, } \\
\text { газа и воды }\end{array}$ & $\begin{array}{c}\text { Индексы } \\
\text { цен произво- } \\
\text { дителей на } \\
\text { строи- } \\
\text { тельную } \\
\text { продук-цию }\end{array}$ & $\begin{array}{c}\text { Индекс } \\
\text { тарифов на } \\
\text { грузовые } \\
\text { перевоз-ки }\end{array}$ \\
\hline \multirow[b]{2}{*}{$\begin{array}{c}\text { Российская Федерация } \\
\text { в т.ч. }\end{array}$} & 105,6 & 102,5 & 101,5 & 106,6 & 105,6 \\
\hline & & & & & \\
\hline Центральный & 106,0 & 101,7 & 103,3 & 105,5 & 103,0 \\
\hline Северо-Западный & 105,6 & 100,5 & 104,4 & 109,2 & 105,4 \\
\hline Южный & 105,4 & 106,6 & 110,1 & 104,5 & 99,8 \\
\hline \multicolumn{6}{|l|}{ Северо-Кавказский } \\
\hline Приволжский & 105,3 & 93,9 & 100,5 & 104,6 & 85,6 \\
\hline Уральский & 104,8 & 101,1 & 98,9 & 105,7 & 109,0 \\
\hline Сибирский & 105,8 & 101,9 & 104,6 & 103,3 & 107,0 \\
\hline \multirow{2}{*}{ Дальневосточный } & 105,5 & 105,0 & 101,5 & 106,6 & 104,1 \\
\hline & 105,7 & 103,8 & 98,9 & 110,0 & 106,7 \\
\hline
\end{tabular}

Данные таблицы 2 свидетельствуют о том, что индексы всех показателей, влияющих на инфляцию издержек, выросли по сравнению с предшествующим годом во всех Федеральных округах, за редким исключением. Приведенные выше данные дают основание утверждать о преобладании инфляции издержек в российской экономике в последние годы.

В связи с особенностями российской экономики и преобладающим значением инфляции издержек, особенно в кризисные годы, органам государственной власти при формировании и реализации экономической политики следует учитывать необходимость использования мер по стимулированию совокупного спроса и развитию национального производства на основе уменьшения процентной ставки, роста инвестиционной активности, увеличения реальных доходов населения, совершенствования системы налогообложения, развития конкуренции и повышения эффективности антимонопольного законодательства.

$$
* * *
$$

1. Ильяшенко В.В. Монетаристская теория и инфляционные процессы в России // Известия Уральского государственного экономического университета. - 2014 г. - № 5 (55). - С. 9.

2. Ильяшенко В.В. Макроэкономические и микроэкономические факторы инфляции в трансформируемой экономике России: Автореф. дис. ... д-ра экон. наук. Екатеринбург, 2007. -47 c.

3. Официальный сайт Федеральной службы государственной статистики. URL: www.gks.ru 